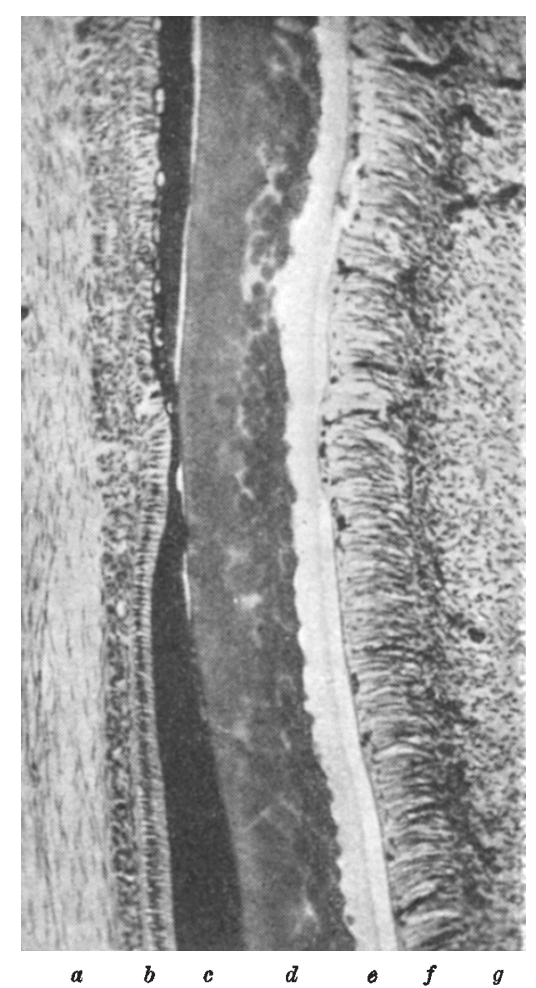

Longitudinal section $(\times 115)$ of the labial side of the upper inciso tooth of a rat which was treated in accordance with the procedure described and was killed eight days after step 4. $a$, labial alveolar periosteum; $b$, enamel organ; $c$, ename matrix ; $d$, dentin; $e$, predentin; $f$, odontoblasts ; $g$, pulp. The formative end of the section is at the bottom. The experimental ameloblasts have recovered as much as possible and the matrix is starting to become acid-soluble, but no new matrix has been formed. The post-experimental ameloblasts are normal and have continued to produce enamel, but the first matrix formed is abnormally narrow. Note sharp demarcation of experimenta

acid-soluble; but a fine fibrous structure, consisting of the walls of the enamel rods, persisted. In spite of the findings of Lefkowitz and his colleagues ${ }^{5}$, and of other workers, I consider that the ameloblasts play a major part in the maturation or secondary calcification of the enamel, and that the pulp is not primarily concerned.

The step in the procedure that originally stopped the experimental ameloblasts from making further matrix is the one which arrested calcification in general. The fact that this stops enamel matrix formation, but not that of bone or dentin, shows that amelogenesis is a fundamentally different process, and is probably bound up with calcification from the start. That such primary calcification of the enamel does occur has been shown by Saunders, Nuckolls and Frisbie $^{6}$, and by Weinmann, Wessinger and Reed ${ }^{7}$. J. T. IRVING

Department of Physiology and Pharmacology, Medical School,

University of Cape Town. Oct. 27.

'Irving, J. T., Nature, 158, 486 (1946).

${ }^{2}$ Bailie, J. M., and Irving, J. T., Brit. J. Exp. Path., 29, 539 (1948),

${ }^{3}$ Weinmann, J. P., J. Amer. Dent. Assoc., 30, 874 (1943).

4 Chase, S. W., Proc. Dent. Cent. Celebr. (Baltimore), 1940, 425.

'Lefkowitz, W., Bodecker, C. F., and Shapiro, H. H., J. Dent. Res. 23, 345 (1944). Lefkowitz, W. Shapiro, H. H., and Bodecker,

- Saunders, J. B. de C. M., Nuckolls, J., and Frisbie, H. E., J. Amer. Coll. Dent., 9, 107 (1942).

'Weinmann, J. P., Wessinger, G. D., and Reed, G., J. Dent. Res., 21, 171 (1942).

\section{A Rapid Permanent Method for Chromosomes}

The difficulty which is usually met with in counterstaining smears and sections stained with Crystal Violet can be largely overcome by the use of 'Cellosolve' (ethylene glycol monoethyl ether) as a dehydrating agent. Crystal and Gentian Violet are considerably less soluble in 'Cellosolve' than alcohol and hence are not removed quite so rapidly from the cells. Provided that the cells are fixed sufficiently, the shrinkage caused by this fluid is negligible.

A rapid method which has proved very efficient is as follows.

(1) Fix root tips, anthers, etc., for 12-24 hr. in Navashin's fluid ; (2) place root tips on a clean slide, previously coated with a thin smear of Mayer's albumen, in a drop of macerating fluid (1 part $\mathrm{HCl} / 1$ part alcohol 95 per cent); warm over spirit lamp about 60 sec.; (3) crush roots or anthers with a scalpel and carefully spread into a smear ; (4) stain $\frac{1}{2}-1 \mathrm{hr}$. in 1 per cent aqueous Crystal Violet; (5) rinse in water; (6) pass slides through two changes of 'Cellosolve', the first containing a trace of Light Groen or Eosin, 4-5 sec. in each (when using Eosin as the counterstain it is often necessary to reduce the time to 3 sec. or less in each); (7) xylene, two changes, $10 \mathrm{~min}$. in each; (8) mount in Canada balsam.

It will be noticed that the lengthy process of washing out the fixative has been omitted. This omission does not lower the quality of the results in any way, but actually assists in retaining the stain. If the counterstain is omitted from the 'Cellosolve', the rate of differentiation can be controlled under low power.

G. W. SHaW

Department of Botany,

University College of North Wales,

Bangor.

Feb. 6.

\section{Occurrence of Chthamalus stellatus in the Isle of Man}

Is the course of a quantitative survey of the Manx intertidal zone, the high-water barnacle, Chthamalus stellatus Poli, was discovered at Port St. Mary and has since been found to be generally distributed around the island. The rediscovery has been thought worth recording in view of the apparent conflict between previous accounts for the area (present: Darwin, $1854^{1}$, Marrat, $1886^{2}$; absent : Moore and Kitching (1934), $1939^{\circ}$ ), and because of the great interest in the species in its more sparse localities.

At ten stations around the Isle of Man, observations were made on the tide-levels occupied, density, and size of Chthamalus. The results for tide-level agree with the findings for other places near the limits of distribution of the species ${ }^{*}$, Chthamalus occupying a zone above the upper Balanus limit (which approximates to high-water neaps plus splash zone, if any) and usually extending to $2-3 \mathrm{ft}$. above and $1 \mathrm{ft}$. below this limit. Density reached a maximum of 100-1,000 per sq. m. at about $1 \mathrm{ft}$. above high-water neaps Size, expressed as a mean of length and breadth of the shell, ranged from $4.75 \mathrm{~mm}$. to $12.25 \mathrm{~mm}$. In spite of the small samples measuredmostly about fifty-it appears that there is a deorease in size towards the north of the island. For example, at the Calf of Man, in the south, the mean of the 